Cite this: Org. Biomol. Chem., 2013, 11, 6856

Received 6th July 2013,

Accepted 29th August 2013

DOI: 10.1039/c3ob41390j

www.rsc.org/obc

\section{Diastereotopic group selectivity and chemoselectivity of alkylidene carbene reactions on 8-oxabicyclo[3.2.1]- oct-6-ene ring systems $\dagger$}

\begin{abstract}
Kevin R. Munro, Louise Male, Neil Spencer and Richard S. Grainger*
$\alpha$-Hydroxyalkylidene carbenes, generated from thermolysis of $\alpha, \beta$-epoxy- $N$-aziridinylimines, undergo diastereotopic group selective 1,5 C-H insertion reactions on 2,4-dimethyl-8-oxabicyclo[3.2.1] oct-6-ene ring systems. Protection of a tertiary alcohol at $\mathrm{C}-3$ of the bridged oxabicycle as a trimethylsilyl ether reverses the sense of diastereoselectivity. 1,5 C-H insertion into a methine adjacent to an OBn group, 1,5 O-R insertion into a tertiary alcohol $(R=H)$ or silylether $(R=T M S)$ at $C-3$ to form spirocyclic dihydrofurans, 1,2-rearrangement to an alkyne and fragmentation to a ketone are competing major pathways for 2-benzyloxy-substituted 8-oxabicyclo[3.2.1]oct-6-ene systems. Dihydrofuran formation is shown to be a result of substitution on the oxabicyclic ring system through comparison with other methods of alkylidene carbene formation.
\end{abstract}

\section{Introduction}

The intramolecular 1,5-alkylidene carbene $\mathrm{C}-\mathrm{H}$ insertion reaction is a powerful method for the synthesis of 5 -membered, unsaturated carbo- and heterocyclic ring systems. ${ }^{1}$ The ability to insert into unfunctionalized $\mathrm{C}-\mathrm{H}$ bonds, with increasingly predictable chemo-, regio- and stereoselectivity, has lead to widespread application in target synthesis. ${ }^{1,2}$

We are interested in the use of this reaction for the preparation of the A-ring of ingenol, a structurally complex diterpene of considerable synthetic and biological interest. ${ }^{3}$ Our previous model studies established that $1,5 \mathrm{C}-\mathrm{H}$ insertion to give cyclopentenes 3 and 6 overrides the potentially competing 1,5 O-Si insertion pathway on structurally rigid 8-oxabicyclo[3.2.1] oct-6-ene ring systems 1 and 4 (Scheme 1). ${ }^{4,5}$ However, these studies did not address the presence of an additional hydroxyl group within the cyclopentene A-ring of the natural product. Keen to avoid the need to introduce the required oxygenation at C-3 (ingenol numbering) post-annulation, we were attracted to the methodology of Kim for the generation of $\alpha$-hydroxyalkylidene carbenes $\mathbf{8}$ through thermolysis of $\alpha, \beta$-epoxy- $N$-aziridinylimines 7 (Scheme 2). ${ }^{6}$ Depending upon substituents $\mathrm{R}^{1}-\mathrm{R}^{3}$, alkylidene carbenes 8 can undergo a

School of Chemistry, University of Birmingham, Edgbaston, Birmingham B15 2TT, UK. E-mail: r.s.grainger@bham.ac.uk; Fax: +44 (0)121 4144403;

Tel: +44 (0)121 4144465

$\dagger$ Electronic supplementary information (ESI) available: Experimental procedures and copies of ${ }^{1} \mathrm{H}$ and ${ }^{13} \mathrm{C}$ NMR for all new compounds. For ESI see DOI: $10.1039 / \mathrm{c} 3 \mathrm{ob} 41390 \mathrm{j}$

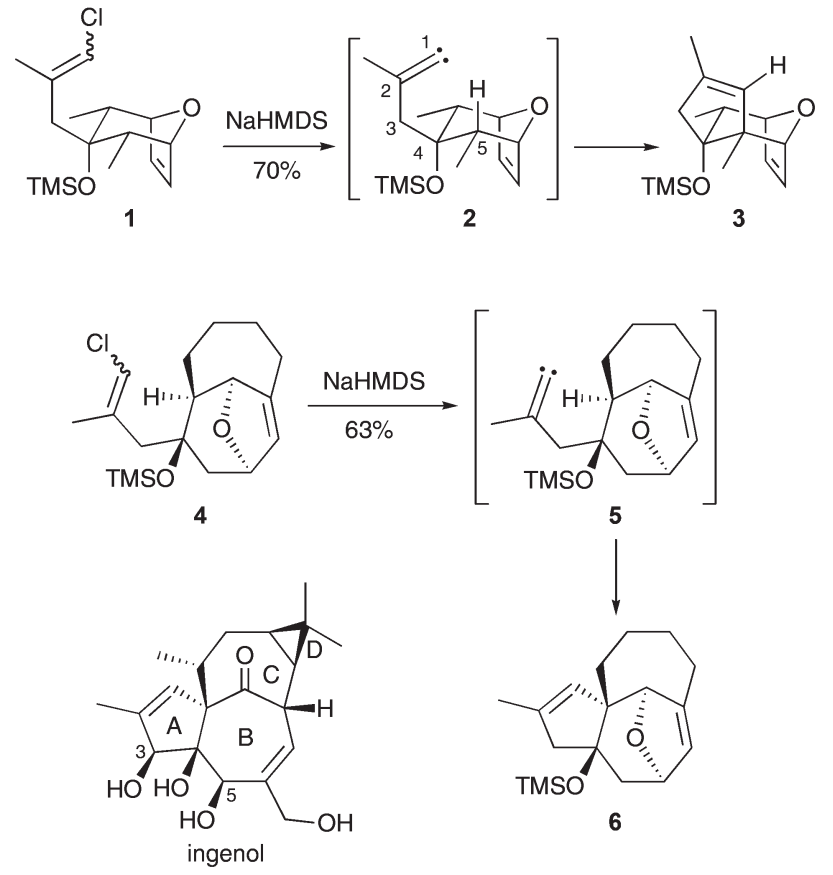

Scheme 1 Previous chemo- and regioselective 1,5 C-H insertion of alkylidene carbenes on 8-oxabicyclo[3.2.1] loct-6-ene ring systems.

number of different reaction pathways, ${ }^{7,8}$ with $1,5 \mathrm{C}-\mathrm{H}$ insertion leading to hydroxy-substituted cyclopentenes. ${ }^{6}$

In this paper we report our studies on the use of the Kim $\alpha$-hydroxyalkylidene carbene for hydroxycyclopentene annula-

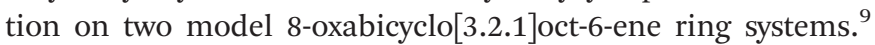


<smiles>[R]C1([R])OC1(/C=C\c1ccccc1)/C=N/N1CC1c1ccccc1</smiles>

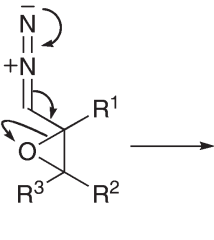<smiles>[R7]C1(P)OC[C@H]2C[N+]2=C1[N+]=[N-]</smiles>
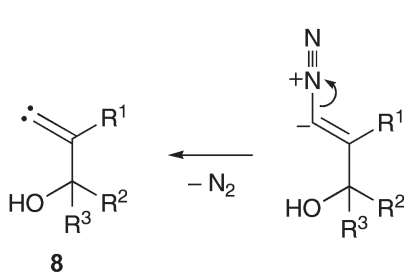

Scheme 2 Formation of $\alpha$-hydroxyalkylidene carbenes 8 from $\alpha, \beta$-epoxy- $N$ aziridinylimines 7

In addition to establishing the compatibility of this methodology on systems bearing oxygen functionality at C-3 of the oxabicycle (a potential site of reactivity), ${ }^{5,7}$ these studies were designed to probe two additional issues. The directing effect of the hydroxyl group in $\mathbf{8}$, initially masked in the form of an epoxide 7 , is investigated through a formal diastereotopic group selective $1,5 \mathrm{C}-\mathrm{H}$ insertion reaction. ${ }^{10,11}$ The influence of additional oxygenation, of relevance to the 5-hydroxyl group in ingenol, is investigated on C-2 benzyloxy-substituted oxabicycles. The formation of products arising from 1,5 $\mathrm{O}-\mathrm{Si}$ and $\mathrm{O}-\mathrm{H}$ insertion reactions on these latter systems are further probed using alternative methods of alkylidene carbene formation.

\section{Results and discussion}

\section{Stereoselective synthesis of alkylidene carbene precursors from oxabicyclo[3.2.1] oct-6-en-3-ones}

The Kim alkylidene carbene precursors, $\alpha, \beta$-epoxy- $N$-aziridinylimines 16a $\left(\mathrm{R}=\mathrm{R}^{\prime}=\mathrm{Me}\right)$ and $16 \mathbf{b}\left(\mathrm{R}=\mathrm{OBn}, \mathrm{R}^{\prime}=\mathrm{H}\right)$, were prepared from the known 8-oxabicyclic ketones $\mathbf{9 a}{ }^{12}$ and $\mathbf{9 b},{ }^{13}$ readily accessible from $[4+3]$ cycloaddition reactions of substituted oxyallylcations with furan (Scheme 3). ${ }^{14}$ Stereoselective addition of the vinyllithium species generated from iodoalkene $10,{ }^{15}$ syn to the oxygen bridge, followed by removal of the TBS group in situ, gave the allylic diol 11. Vanadium-catalysed epoxidation allowed for selective oxidation of the exocyclic alkene in $11 a^{16}$ In contrast, $m$-CPBA gave a mixture of products arising from additional reaction at the endocyclic alkene. The presence of a primary alcohol is also important to achieve the desired chemoselectivity - the corresponding TBS ether of 11a (containing a tertiary alcohol) failed to undergo vanadium-catalysed epoxidation at either alkene. Vanadiumcatalysed oxidation of allylic alcohol 11b proceeded with 9:1 diastereoselectivity in favour of epoxide $\mathbf{1 2} \mathbf{b}$, the relative stereochemistry of which was confirmed on a later compound. The preferential formation of $\mathbf{1 2 b}$ can be ascribed to epoxidation occurring through a conformation $\mathbf{1 1} \mathbf{b}^{\prime}$ where both the benzyl

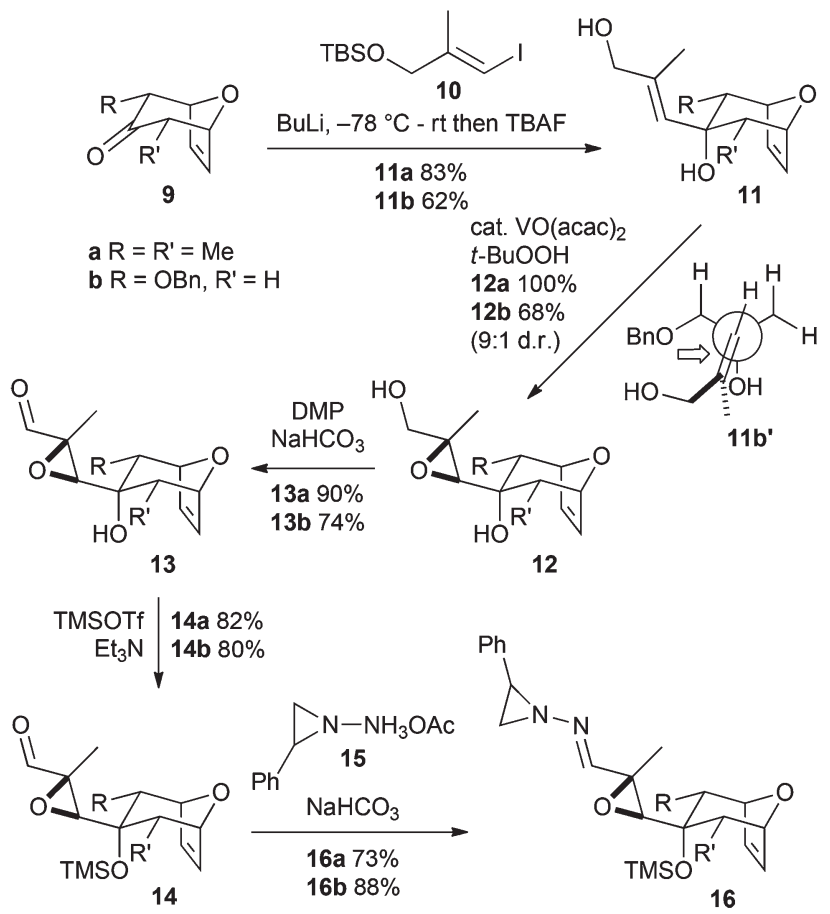

Scheme 3 Synthesis of alkylidene carbene precursors $\mathbf{1 6 a}$ and $\mathbf{1 6 b}$.

ether and the primary alcohol can coordinate vanadium. ${ }^{17}$ Further oxidation of the primary alcohol of 12 using DessMartin periodinane (DMP) in the presence of $\mathrm{NaHCO}_{3}$ gave the aldehyde $13 .{ }^{18}$ Protection of the tertiary alcohol as a TMS ether 14 followed by condensation with the hydrazine derived from ammonium salt $15^{19}$ gave the target $N$-aziridinylimine 16.

\section{Diastereotopic group selective alkylidene carbene 1,5 C-H insertion reactions on 2,4-dimethyl-8-oxabicyclo[3.2.1] oct-6- enes}

Heating a toluene solution of $\mathbf{1 6 a}$ to reflux gave rise to a mixture of two diastereomeric cyclopentenols 18 and 19 in $64 \%$ overall yield, consistent with the generation and subsequent 1,5 $\mathrm{C}-\mathrm{H}$ insertion of $\alpha$-hydroxyalkylidene carbene $\mathbf{1 7 a}$ (Scheme 4). The two diastereoisomers 18 and 19 were separable by column chromatography, and their relative stereochemistry determined by nOe analysis. In the case of the minor isomer 19, correlation is observed between the proton adjacent to the alcohol and the axial methine hydrogen on the tetrahydropyran ring, whereas no analogous signal is observed in the major isomer 18.

Deprotection of the trimethylsilylether in 16a with TBAF gave the tertiary alcohol 20a in excellent yield (Scheme 4). The tertiary alcohol 20a also gave rise to a mixture of cyclopentenols 22 and 23 upon heating to reflux in toluene, in lower overall yield $(42 \%)$ and with the reversed sense of diastereoselectivity $(1: 2$ ratio $22: 23)$ compared with the thermolysis of silylether 16a to give cyclopentenols 18 and 19 (64\%, 2:1 ratio 18:19). Cyclopentenols 22 and 23 were isolable by column chromatography, and relative stereochemistry was again 


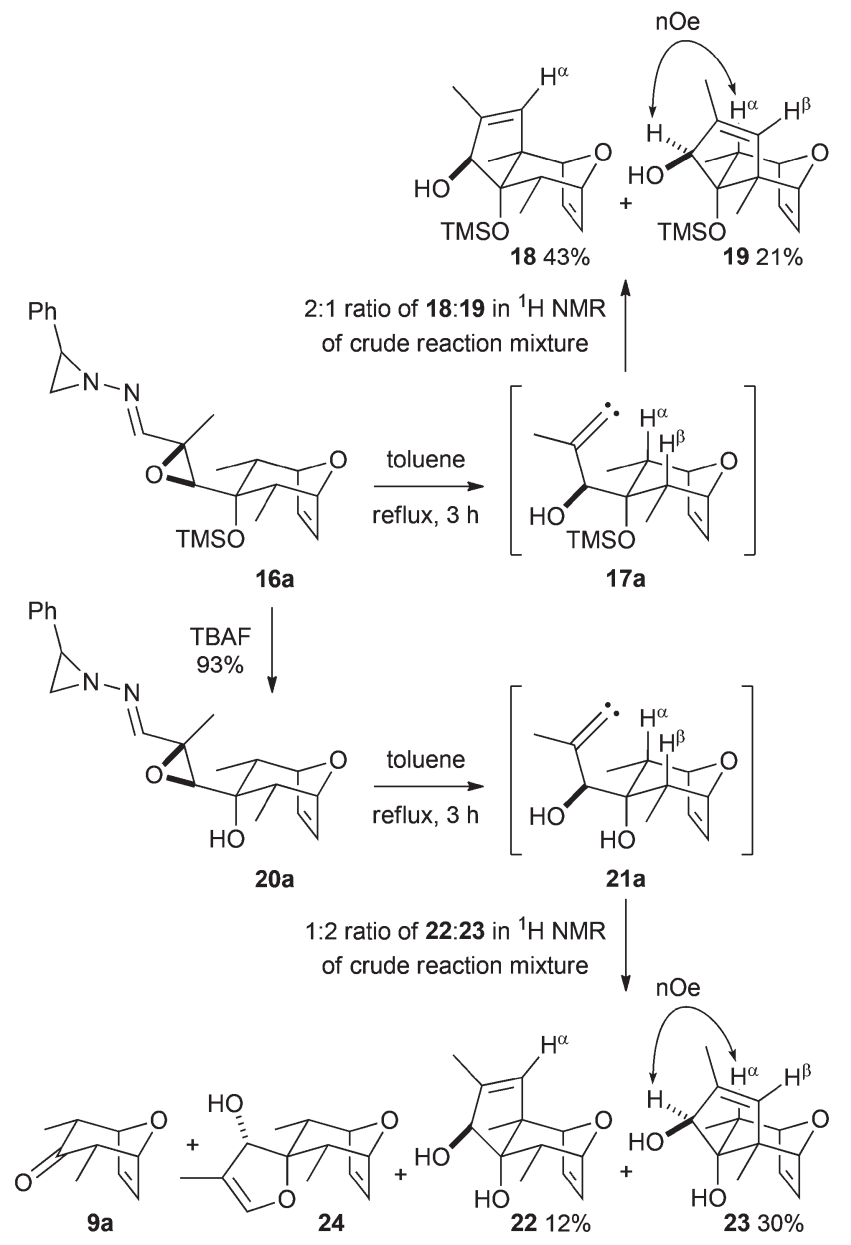

Scheme 4 Diastereotopic group selective $1,5 \mathrm{C}-\mathrm{H}$ insertion reactions of $\alpha$-hydroxyalkylidene carbenes $\mathbf{1 7 a}$ and $\mathbf{2 1 a}$.

determined by nOe correlation in the major diol $\mathbf{2 3}$, with the structure of the minor diol 22 further confirmed by X-ray analysis (Fig. 1). ${ }^{1} \mathrm{H}$ NMR of the crude reaction mixture also showed the presence of dihydrofuran 24 , the product of 1,5 $\mathrm{O}-\mathrm{H}$ insertion, and surprisingly the ketone $9 \mathrm{a}$, the product of $\mathrm{C}-\mathrm{C}$ bond fragmentation. The ratio of $\mathrm{C}-\mathrm{H}$ insertion products 22 and 23 to both 24 and 9a was approximately $6: 1$ by integration of characteristic peaks in the ${ }^{1} \mathrm{H}$ NMR of the crude reaction mixture.

The diastereoselectivity of the $1,5 \mathrm{C}-\mathrm{H}$ insertion reaction is clearly dependent on the C-3 substituent of the oxabicycle, and while modest, is notably reversed for silylether 16a and alcohol 20a. The alcohol stereocentre in alkylidene carbenes 17a and 21a renders the two potential bonds for 1,5 $\mathrm{C}-\mathrm{H}$ insertion, $\mathrm{C}-\mathrm{H}^{\alpha}$ and $\mathrm{C}-\mathrm{H}^{\beta}$, diastereotopic. The diastereotopic group selectivity ${ }^{20,21}$ is controlled by the preferred orientation about

$\ddagger 22: \mathrm{C}_{13} \mathrm{H}_{18} \mathrm{O}_{3}, M=222.27$, orthorhombic, $a=13.4833(5), b=11.3687(5), c=$ 14.6074(8) $\AA, U=2239.13(18) \AA^{3}, T=120(2) \mathrm{K}$, space group $P b c a, Z=8,24957$ reflections measured, 2558 unique $\left(R_{\text {int }}=0.0685\right)$ which were used in all calculations. The final $R_{1}$ was $0.0494(I>2 \sigma(I))$ and $\mathrm{w} R\left(F_{2}\right)$ was 0.1200 (all data). CCDC 946066 contains the supplementary crystallographic data for this paper.

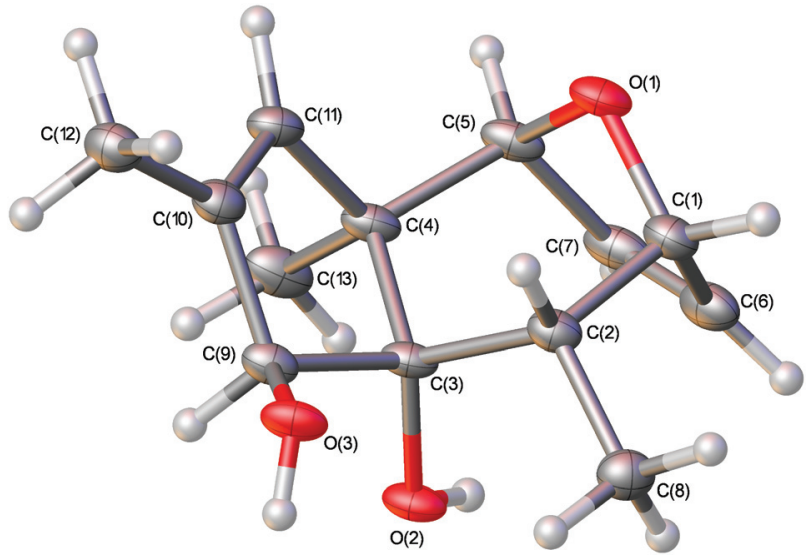

Fig. 1 Crystal structure of hydroxycyclopentene $\mathbf{2 2}$ with ellipsoids drawn at the $50 \%$ probability level.
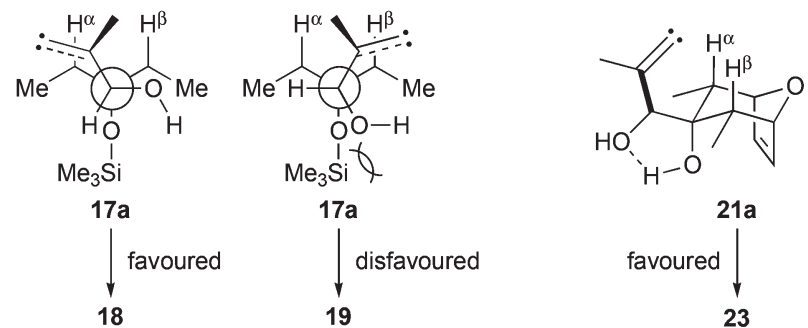

Scheme 5 Stereochemical rationale for diastereotopic group selective $\mathrm{C}-\mathrm{H}$ insertion.

the $\mathrm{HO}-\mathrm{C}-\mathrm{C}-\mathrm{OR}$ carbon-carbon bond within the carbene (Scheme 5). For the TMS ether 17a, insertion into $\mathrm{C}-\mathrm{H}^{\beta}$ is disfavoured compared to insertion into $\mathrm{C}-\mathrm{H}^{\alpha}$, presumably due to unfavourable steric and/or electronic interactions between the silyl ether and the alcohol. For the tertiary alcohol 21a, preferential insertion into $\mathrm{C}-\mathrm{H}^{\beta}$ can be rationalized by invoking a hydrogen bonding interaction, which fixes the conformation about the vicinal diol and orients the alkylidene carbene towards $\mathrm{C}-\mathrm{H}^{\beta}$.

Attempts were made to increase the diastereoselectivity through functionalisation of the tertiary alcohol in 13a with either a bulkier silyl group or an ester, which might alternatively act as a H-bond acceptor to the developing alcohol. Unfortunately the hindered nature of the tertiary alcohol in 13a made it recalcitrant to reaction with TIPSOTf, TESOTf, $\mathrm{AcCl}, \mathrm{Cl}_{2} \mathrm{CHCOCl}$ or $\mathrm{CF}_{3} \mathrm{COCl}$.

Further attempts to exploit an attractive interaction such as that proposed for 21a (Scheme 5) instead promoted the unusual $\mathrm{C}-\mathrm{C}$ bond fragmentation pathway leading to ketone 9a. Running the thermolysis of 20a in the presence of LiHMDS (to form a metal chelate) or phenylboronic acid (to form a cyclic boronate in situ $^{22}$ ) gave 9a in $22 \%$ and $52 \%$ isolated yield respectively, with no evidence of formation of 1,5 insertion products of an alkylidene carbene (Scheme 6). Alkoxysilylcyclobutane 26, expected to be Lewis acidic at Si through relief of ring strain, ${ }^{23}$ was prepared in two steps from 13a (yields 


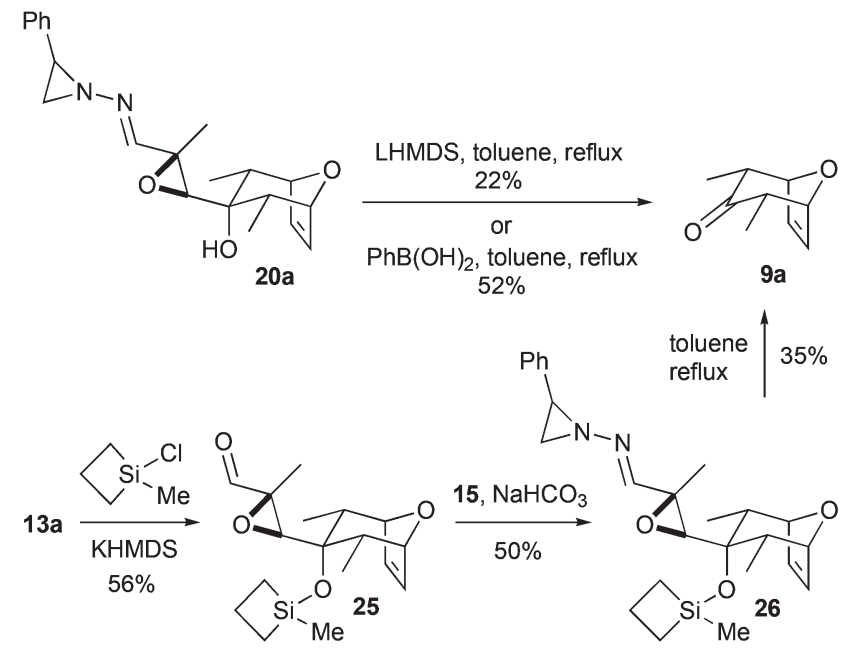

Scheme 6 Fragmentation to ketone 9 a

unoptimized). Again refluxing 26 in toluene resulted in fragmentation to form the ketone 9a. Although the mechanism of this fragmentation has not been elucidated, a common factor may be the possible impedance of the proton transfer step in alkylidene carbene formation (Scheme 2), allowing alternative pathways to dominate. ${ }^{24}$ This unusual pathway was further demonstrated to be a function of the aziridinylimine - the epoxy aldehyde 25 proved stable to refluxing toluene, and could be recovered in good yield.

\section{Chemoselectivity in $\alpha$-hydroxyalkylidene carbene insertion reactions on 2-benzyloxy-8-oxabicyclo[3.2.1] $]$ oct-6-enes}

Thermolysis of the TMS ether $\mathbf{1 6 b}$ gave a relatively complex mixture of products, from which hydroxycyclopentene 27 , the product of 1,5 C-H insertion of alkylidene carbene $\mathbf{1 7} \mathbf{b}$ adjacent to oxygen, could be isolated in $41 \%$ yield (Scheme 7 ).

nOe analysis of 27 showed a correlation between the proton adjacent to the hydroxyl group and one of the benzylic hydrogens, thus establishing the stereochemistry of major epoxide 12b in the synthetic route to $\mathbf{1 6 b}$ (Scheme 3 ). ${ }^{1} \mathrm{H}$ NMR analysis of the crude reaction mixture showed 27 to be the major product, obtained in an approximately $2.4: 1: 1.2$ ratio along with silyldihydrofuran 28 , the product of $1,5 \mathrm{O}-\mathrm{Si}$ insertion, and the ketone $9 \mathrm{~b}$, the product of $\mathrm{C}-\mathrm{C}$ bond fragmentation. The structure of $\mathbf{2 8}$ within the reaction mixture was assigned on the basis of comparison with related tetrahydrofurans (vide infra), however it could not be separated by column chromatography. The combined yield of 27,28 and $9 \mathbf{b}$ was $79 \%$.

Removal of the TMS group from $\mathbf{1 6 b}$ with TBAF gave the tertiary alcohol 20b, which could not be adequately purified by column chromatography and so was instead taken directly into the thermolysis reaction to form the $\alpha$-hydroxyalkylidene carbene $\mathbf{2 1 b}$. Heating a toluene solution of the crude tertiary alcohol 20b at reflux also gave rise to a relatively complex mixture of products, which could, however, be separated by column chromatography. Hydroxycyclopentene 29, arising from 1,5 C-H insertion next to oxygen, and dihydrofuran $\mathbf{3 0}$,
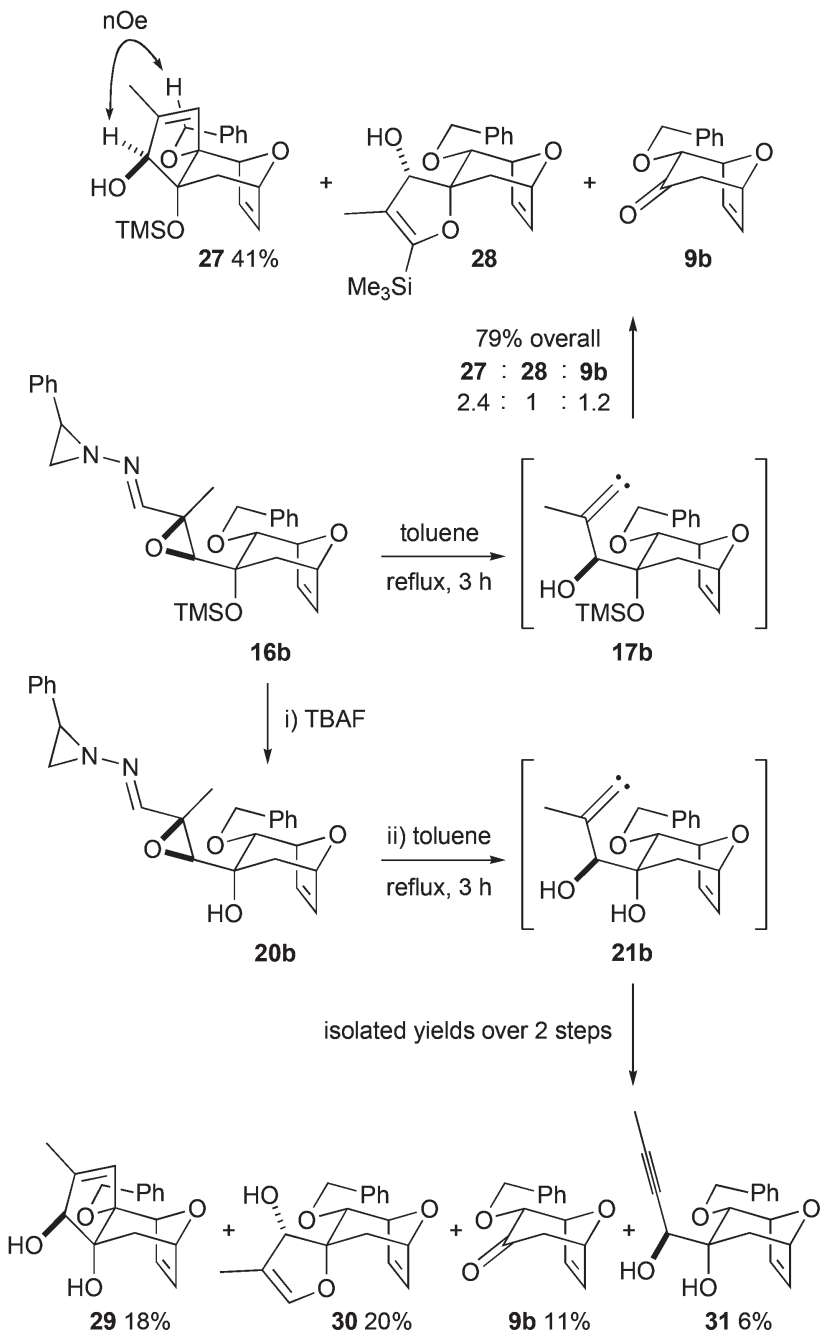

Scheme 7 Regio- and chemoselectivity in alkylidene carbene insertion on 2-benzyloxy-substituted 8-oxabicyclo[3.2.1]oct-6-ene ring systems.

the product of $\mathrm{O}-\mathrm{H}$ insertion, were the two major compounds, formed in an approximately 1:1 ratio. Significant amounts of ketone 9b were again formed, and it was also possible to isolate small quantities of the alkyne $\mathbf{3 1}$, the product of 1,2rearrangement of the intermediate alkylidene carbene.

Alkylidene carbenes show a general preference for insertion into more substituted $\mathrm{C}-\mathrm{H}$ bonds, tertiary > secondary > primary, a trend which is rationalized by the interaction of the more electron-rich $\mathrm{C}-\mathrm{H}$ bond with the electron-deficient carbene. $^{25}$ The preferential 1,5-insertion of alkylidene carbenes into $\mathrm{C}-\mathrm{H}$ bonds adjacent to heteroatoms is also well established in the literature. A recent comprehensive study by Lee has shown there is a directionality to the activating effect of an oxygen on an adjacent $\mathrm{C}-\mathrm{H}$ bond. An ether oxygen can activate an adjacent $\mathrm{C}-\mathrm{H}$ bond towards insertion through lonepair donation into the $\sigma_{\mathrm{C}-\mathrm{H}}^{*}$ antibonding orbital when appropriately aligned. ${ }^{2}$ For both $\mathbf{1 7 b}$ and $\mathbf{2 1 b} \mathbf{b}, 5 \mathrm{C}-\mathrm{H}$ insertion is completely selective for insertion into the methine group adjacent to the benzylic oxygen over the alternative $1,5 \mathrm{C}-\mathrm{H}$ insertion into the methylene group. The electronic and 
stereoelectronic activation of the tertiary $\mathrm{C}-\mathrm{H}$ apparently overrides, or acts in concert with, any potential directing effect of the alcohol stereocentre in $\mathbf{1 7} \mathbf{b}$ and $\mathbf{2 1 b}$.

More surprising is the increased predominance of additional reaction pathways observed for the 2-benzyloxysubstituted oxabicyclo[3.2.1] oct-6-ene ring systems $\mathbf{1 6 b}$ and 20b compared to the 2,4-dimethyl-substituted systems 16a and 20a. Analogous $\mathrm{O}-\mathrm{Si} / \mathrm{O}-\mathrm{H}$ insertion, fragmentation to ketone 9a, and 1,2-migration are all pathways available to $\mathbf{1 6 a}$ and 20a, yet only occurred to a minor extent, or not at all. 1,2-Alkyl migration in particular is rarely observed for dialkyl-substituted alkylidene carbenes. ${ }^{10 e, 26,27}$ Either $1,5 \mathrm{C}-\mathrm{H}$ insertion is slower than might be expected based on the additional stereoelectronic activation by the OBn group compared to the methyl groups in 17a and 21a, or structural features in the benzyloxysubstituted system promote these competing reaction pathways.

\section{Comparison with other methods of alkylidene carbene generation}

We do not have a satisfactory rationale for this divergence in reactivity with substitution pattern, but the formation of significant quantities of enol ethers $\mathbf{2 8}$ and $\mathbf{3 0}$ is perhaps not as surprising as the fact that products arising from formal 1,5 O-Si were not observed in the thermolysis of 16a, and the formation of dihydrofuran $\mathbf{2 4}$ from $\mathrm{O}-\mathrm{H}$ insertion is only a minor pathway in the thermolysis 20a (Scheme 4). Previous studies have shown that 1,5 $\mathrm{O}-\mathrm{Si}$ and $\mathrm{O}-\mathrm{H}$ insertion generally predominates over $1,5 \mathrm{C}-\mathrm{H}$ insertion where both pathways can operate. $^{7,28}$

We have previously ${ }^{5}$ ascribed the lack of O-Si insertion in the alkyl-substituted oxabicycles 1 and $\mathbf{4}$ (Scheme 1) to the preferred geometry about the $\mathrm{C}-\mathrm{OSiMe}_{3}$ bond, which orients the lone pairs on oxygen away from the alkylidene carbene (represented as the free carbenes 2 and 5 , but better envisioned as metal carbenoids ${ }^{29}$ ). Why then should $\mathrm{O}-\mathrm{Si}$ and $\mathrm{O}-\mathrm{H}$ insertion be favoured to such an extent for the benzyloxy-substituted systems? While the nature of the alkylidene carbene is different to that shown in Scheme 1, and the higher temperature at which it is being generated should increase bond rotation and may allow these alternative pathways to operate, this does not explain the lack of $\mathrm{O}-\mathrm{Si}$ insertion in 16a, and the relatively small amount of $\mathrm{O}-\mathrm{H}$ insertion observed for 20a. In order to separate any potential role of the developing hydroxyl group in directing the product outcome, e.g. through hydrogen bonding with the benzylic oxygen which may orientate the carbene away from the $\mathrm{C}-\mathrm{H}$ insertion site, we have extended our prior studies in systems lacking this feature. In this way we hoped to determine the relative importance of the structure of the oxabicyclic vs. the nature of the carbene generation method on the product outcome. ${ }^{30}$ Two classical methods of carbene generation were chosen, the base-mediated $\alpha$-elimination of a chloroalkene, and the reaction of a ketone with lithiated trimethylsilyldiazomethane, which generates the carbene through sequential Peterson olefination and loss of nitrogen. ${ }^{2,31}$
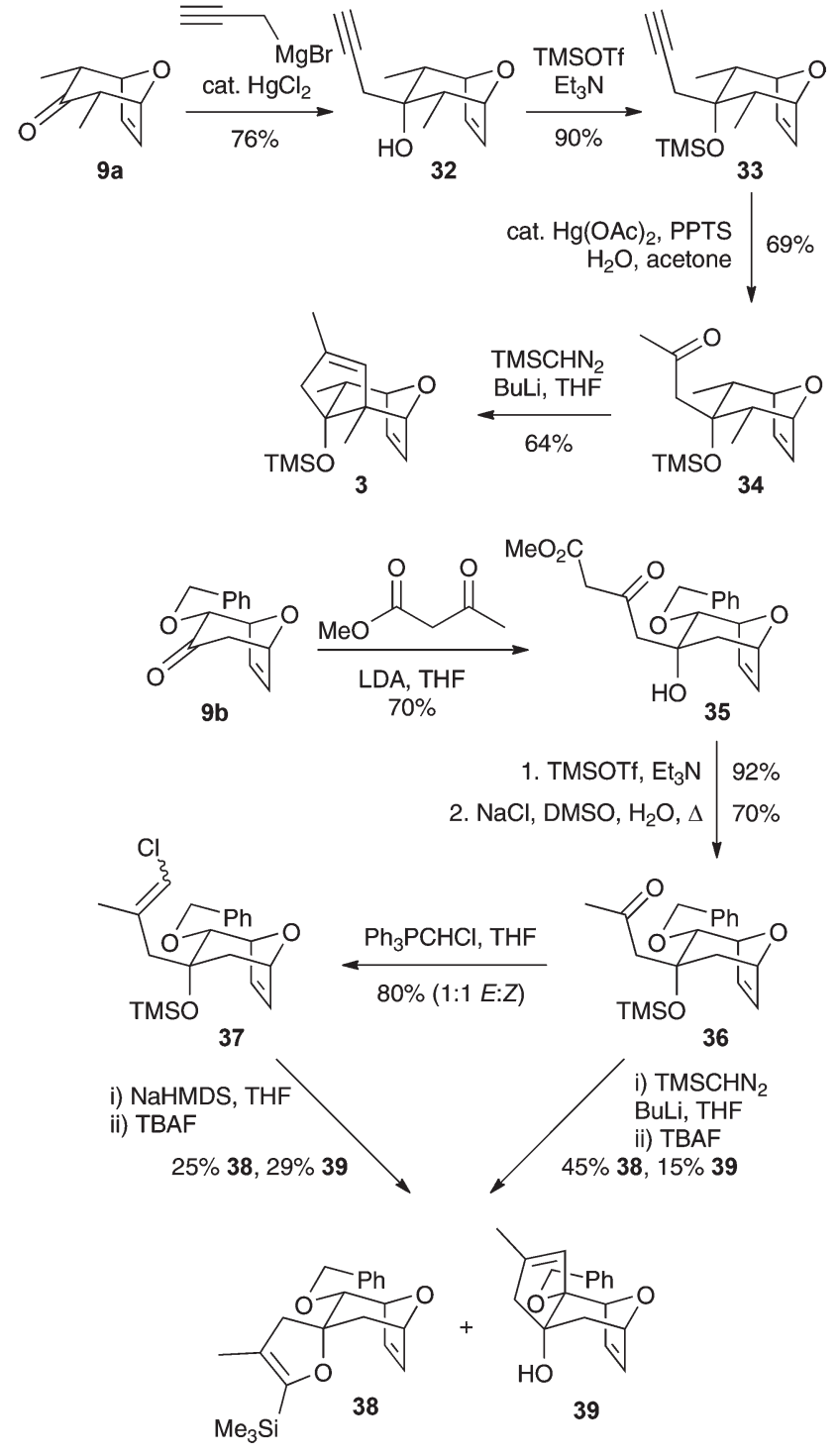

Scheme 8 Alternative methods of alkylidene carbene generation.

$\beta$-Silyloxyketone 34 was prepared in three steps from 2,4-dimethyl-8-oxabicyclo[3.2.1] oct-6-ene (9a) as previously described (Scheme 8). ${ }^{5}$ Treatment of ketone 34 with lithium (trimethylsilyl)diazomethane gave cyclopentene 3 , the same product of $\mathrm{C}-\mathrm{H}$ insertion we observed when generating the carbene from deprotonation of chloroalkene 1 (Scheme 1). Hence all three carbene generation methods on the 2,4dimethyl-3-trimethylsilyloxy-substituted oxabicyclic systems give products of 1,5 $\mathrm{C}-\mathrm{H}$ insertion, with no evidence of significant dihydrofuran formation through 1,5 O-Si insertion.

For the 2-benzyloxy-substituted system we employed a route previously developed for the synthesis of chloroalkene $\mathbf{4}$ (Scheme 1). ${ }^{5}$ Addition of the dianion of methylacetoacetate to ketone $\mathbf{9 b}$ gave $\beta$-ketoester $\mathbf{3 5}$ in good yield. Protection of the tertiary alcohol as a trimethylsilylether followed by Krapcho decarboxylation gave the $\beta$-silyloxyketone 36. Subsequent Wittig reaction gave chloroalkene 37 as a 1:1 mixture of double bond isomers (Scheme 8). 
The alkylidene carbenes generated from both 36 and 37 gave a mixture of compounds arising from both 1,5 $\mathrm{C}-\mathrm{H}$ insertion and 1,5 $\mathrm{O}-\mathrm{Si}$ insertion, which were separable after treatment of the crude reaction mixture with TBAF to liberate the tertiary alcohol 39. The ratio of 38:39 changes with the method of carbene generation. Using lithium (trimethylsilyl)diazomethane $\mathrm{O}-\mathrm{Si}$ insertion to give $\mathbf{3 8}$ is the dominant reaction pathway, whereas cyclopentene 39 is slightly favoured through deprotonation of chloroalkene 37. Although there is a difference in product ratio with the method of generation of the carbene, ${ }^{30}$ these results, and those using the Kim alkylidene carbene precursor, show a clear overall trend. The presence of a benzyloxy-substituent at C-2 of the oxabicyclic ring system controls the regioselectivity of $1,5 \mathrm{C}-\mathrm{H}$ insertion, but also leads to significant quantities of 1,5 O-Si insertion, irrespective of the method of carbene generation. In neither case was fragmentation to ketone $\mathbf{9 b}$ nor 1,2-rearrangement to an alkyne observed, suggesting these pathways can be ascribed to the nature of the $\alpha$-hydroxyalkylidene carbene, or the conditions under which it is generated.

\section{Conclusions}

Stereocontrolled annulation of hydroxycyclopentenes onto 8-oxabicyclo[3-2.1] oct-6-en-3-ones can be achieved using Kim's alkylidene carbene methodology, thus increasing the utility of these readily accessible and synthetically versatile ring systems. ${ }^{9,32}$ A benzyloxy group at C-2 of the oxabicycle controls the position 1,5 $\mathrm{C}-\mathrm{H}$ insertion, but results in increased amounts of products arising from alternative reaction pathways, compared with 2,4-dimethyl-substituted systems. Formation of spirocyclic dihydrofurans in 2-benzyloxy-substituted oxabicycles occurs irrespective of the type of alkylidene carbene employed, and is the dominant reaction pathway using lithium trimethylsilyldiazomethane. Additional reaction pathways, including a previously unobserved $\mathrm{C}-\mathrm{C}$ bond fragmentation, occur upon heating $\alpha, \beta$-epoxy- $N$-aziridinylimines in refluxing toluene, compared to systems where the alkylidene carbene is generated at lower temperatures, and which lack an $\alpha$-hydroxyl group.

\section{Acknowledgements}

We thank the EPSRC and University of Birmingham for funding. We thank the EPSRC UK National Crystallography Service at the University of Southampton for the collection of the crystallographic data. ${ }^{33}$ The NMR spectrometers used in this research were obtained through Birmingham Science City: Innovative Uses for Advanced Materials in the Modern World (West Midlands Centre for Advanced Materials Project 2), with support from Advantage West Midlands (AWM) and part funded by the European Regional Development Fund (ERDF).

\section{Notes and references}

1 For reviews on alkylidene carbenes see: W. Kirmse, Angew. Chem., Int. Ed. Engl., 1997, 36, 1164; R. Knorr, Chem. Rev., 2004, 104, 3795.

2 For lead references see: J.-C. Zheng, S. Y. Yun, C. Sun, N.-K. Lee and D. Lee, J. Org. Chem., 2011, 76, 1086.

3 For reviews on the total synthesis of ingenol see: I. Kuwajima and K. Tanino, Chem. Rev., 2005, 105, 4661; J. K. Cha and O. L. Epstein, Tetrahedron, 2006, 62, 1329; T. Busch and A. Kirschning, Nat. Prod. Rep., 2008, 25, 318.

4 R. S. Grainger, R. B. Owoare, P. Tisselli and J. W. Steed, J. Org. Chem., 2003, 68, 7899.

5 R. S. Grainger and R. B. Owoare, Org. Lett., 2004, 6, 2961.

6 S. Kim and C. M. Cho, Tetrahedron Lett., 1994, 35, 8405.

7 S. Kim and C. M. Cho, Tetrahedron Lett., 1995, 36, 4845.

8 H.-Y. Lee and Y. Kim, J. Am. Chem. Soc., 2003, 125, 10156.

9 For reviews on the synthetic utility of 8-oxabicyclo[3.2.1] oct6-en-3-one ring systems see: P. Chiu and M. Lautens, in Topics in Current Chemistry, ed. P. Metz, Springer-Verlag, New York, 1997, vol. 190, pp. 1-85; I. V. Hartung and H. M. R. Hoffmann, Angew. Chem., Int. Ed., 2004, 43, 1934.

10 For previous examples of regio- and diastereoselective alkylidene carbene $1,5 \mathrm{C}-\mathrm{H}$ insertion reactions controlled by an existing stereocentre in the connecting chain see: (a) D. F. Taber and R. P. Meagley, Tetrahedron Lett., 1994, 35, 7909; (b) S. Ohira, T. Sawamoto and M. Yamato, Tetrahedron Lett., 1995, 36, 1537; (c) D. F. Taber and H. Yu, J. Org. Chem., 1997, 62, 1687; (d) D. F. Taber, T. E. Christos, T. D. Neubert and D. Batra, J. Org. Chem., 1999, 64, 9673; (e) L. F. Walker, A. Bourghida, S. Connolly and M. Wills, J. Chem. Soc., Perkin Trans. 1, 2002, 965; (f) G. Hobley, K. Stuttle and M. Wills, Tetrahedron, 2003, 59, 4739; (g) A. N. Van Nhien, E. Soriano, J. Marco-Contelles and D. Postel, Carbohydr. Res., 2009, 344, 1605; (h) A. N. Van Nhien, R. Cordonnier, M.-D. Le Bas, S. Delacroix, E. Soriano, J. Marco-Contelles and D. Postel, Tetrahedron, 2009, 65, 9378; (i) S. Lee and H.-Y. Lee, Bull. Korean Chem. Soc., 2010, 31, 557.

11 For desymmetrization of 8-oxabicyclic[3.2.1] octane ring systems through metal-catalysed asymmetric intramolecular C-H insertion see: P. Chiu, X. Zhang and R. Y. Y. Ko, Tetrahedron Lett., 2004, 45, 1531; X. Zhang, Z. Li, J. C. K. Chu and P. Chiu, Tetrahedron Lett., 2011, 52, 6763.

12 M. Lautens and G. Bouchain, Org. Synth., 2002, 79, 251.

13 M. Vidal-Pascual, C. Martínez-Lamenca and H. M. R. Hoffmann, Org. Synth., 2006, 83, 61.

14 For recent reviews on the $[4+3]$ cycloaddition reaction see: M. Harmata, Chem. Commun., 2010, 46, 8886; M. Harmata, Chem. Commun., 2010, 46, 8904; A. G. Lohse and R. P. Hsung, Chem.-Eur. J., 2011, 17, 3812.

15 R. Baker and J. L. Castro, J. Chem. Soc., Perkin Trans. 1, 1990, 47; G. R. Scarlato, J. A. DeMattei, L. S. Chong, A. K. Ogawa, M. R. Lin and R. W. Armstrong, J. Org. Chem., 1996, 61, 6139; T. Motozaki, K. Sawamura, A. Suzuki, 
K. Yoshida, T. Ueki, A. Ohara, R. Munakata, K.-i. Takao and K.-i. Tadano, Org. Lett., 2005, 7, 2261.

16 K. B. Sharpless and R. C. Michaelson, J. Am. Chem. Soc., 1973, 95, 6136.

17 M. Kitamura, M. Isobe, Y. Ichikawa and T. Goto, J. Org. Chem., 1984, 49, 3517.

18 A. Fürstner, O. Larionov and S. Flügge, Angew. Chem., Int. Ed., 2007, 46, 5545.

19 R. K. Müller, R. Joos, D. Felix, J. Schreiber, C. Wintner and A. Eschenmoser, Org. Synth., 1976, 55, 114.

20 For reviews on diastereotopic group selective reactions see: R. W. Hoffmann, Synthesis, 2004, 2075; P. Herrmann and T. Bach, Chem. Soc. Rev., 2011, 40, 2022.

21 For previous contributions from our group in the area of diastereotopic group selective reactions see: R. S. Grainger, P. Tisselli and J. W. Steed, Org. Biomol. Chem., 2004, 2, 151; T. C. Casey, J. Carlisle, P. Tisselli, L. Male, N. Spencer and R. S. Grainger, J. Org. Chem., 2010, 75, 7461.

22 P. J. Duggan and E. M. Tyndall, J. Chem. Soc., Perkin Trans. 1, 2002, 1325.

23 A. G. Myers, S. E. Kephart and H. Chen, J. Am. Chem. Soc., 1992, 114, 7922; S. E. Denmark, B. D. Griedel, D. M. Coe and M. E. Schnute, J. Am. Chem. Soc., 1994, 116, 7026; K. Matsumoto, K. Oshima and K. Utimoto, J. Org. Chem., 1994, 59, 7152.

24 For a review on the chemistry of $N$-aziridinylimines see: W. Kirmse, Eur. J. Org. Chem., 1998, 201.

25 J. Wolinsky, G. W. Clark and P. C. Thorstenson, J. Org. Chem., 1976, 41, 745; J. C. Gilbert, D. H. Giamalva and U. Weerasooriya, J. Org. Chem., 1983, 48, 5251.

26 D. J. Wardrop and E. G. Bowen, Chem. Commun., 2005, 5106.

27 Alkyne 30 can arise through formal migration of either a methyl group or a hydroxyalkyl group. Wills has discussed the relative migratory aptitude of methyl $v s$. isopropyl $v s$. alkoxy towards alkylidene carbenes: ref. $10 e$.

28 K. Miwa, T. Aoyama and T. Shioiri, Synlett, 1994, 461; K. S. Feldman and M. L. Wrobleski, J. Org. Chem., 2000, 65, 8659; H.-J. Gais, L. R. Reddy, G. S. Babu and G. Raabe, J. Am. Chem. Soc., 2004, 126, 4859. For an exception see ref. $10 f$.

29 M. Braun, Angew. Chem., Int. Ed., 1998, 37, 430.

30 For an example of where the method of generation of the alkylidene carbene changes the regioselectivity of $1,5 \mathrm{C}-\mathrm{H}$ insertion see: D. F. Taber and T. E. Christos, Tetrahedron Lett., 1997, 38, 4927.

31 S. Ohira, K. Okai and T. Moritani, J. Chem. Soc., Chem. Commun., 1992, 721; D. J. Wardrop, W. M. Zhang and J. Fritz, Org. Lett., 2002, 4, 489; C. J. Hayes, D. A. Bradley and N. A. Thomson, J. Org. Chem., 2006, 71, 2661.

32 For representative methodology and application of cyclopentane annulation on 8-oxabicyclo[3.2.1] octan-3-one ring systems see: Á. M. Montaña and K. M. Nicholas, J. Org. Chem., 1990, 55, 1569; P. A. Wender and F. E. McDonald, J. Am. Chem. Soc., 1990, 112, 4956; M. Nowakowski and H. M. R. Hoffmann, Tetrahedron, 1997, 53, 4331; G. A. Molander and S. C. Jeffrey, Tetrahedron Lett., 2002, 43, 359; G. A. Molander, B. Czakó and D. J. St. Jean Jr., J. Org. Chem., 2006, 71, 1172; Á. M. Montaña, S. Ponzano, G. Kociok-Köhn, M. Font-Bardia and X. Solans, Eur. J. Org. Chem., 2007, 4383; J. Xu, E. J. E. Caro-Diaz and E. A. Theodorakis, Org. Lett., 2010, 12, 3708; Á. M. Montaña, S. Ponzano, C. Batalla and M. Font-Bardia, Tetrahedron, 2012, 68, 8276; J. Wang, S.-G. Chen, B.-F. Sun, G.-Q. Lin and Y.-J. Shang, Chem.-Eur. J., 2013, 19, 2539.

33 S. J. Coles and P. A. Gale, Chem. Sci., 2012, 3, 683. 